\title{
Negative Regulation of Antioxidant Enzyme Gene Expression in the Developing Fetal Rat Lung by Prenatal Hormonal Treatments
}

\author{
YOUWEI CHEN, PHILIP L. WHITNEY. AND LEE FRANK \\ Pulmonary Research ('onler. Departments of Medicine and Pediatrics, University of Miami School of hedicine. \\ Miami. Florida 33101
}

\begin{abstract}
Prenatal administration of thyrotropin-releasing hormone (TRH) or TRH plus dexamethasone (DEX) to pregnant rats accelerates lung surfactant system development in late gestation, but paradoxically depresses the normal late gestational elevation in fetal lung antioxidant enzyme (AOE) activities (Pediatr Res 30:522, 1991). In these present studies, we tested whether both prenatal hormonal treatments act to depress normal fetal lung $\mathrm{AOE}$ development by negative regulation of $\mathrm{AOE}$ gene expression. We used solution hybridization to quantitate the concentration of AOE mRNA. Results of the developmental studies revealed significantly decreased lung mRNA concentrations of copper-zinc superoxide dismutase, manganese superoxide dismutase, catalase, and glutathione peroxidase in late gestation as a result of prenatal TRH treatment. The addition of DEX administration did not reverse the lowered expression of lung $\mathrm{AOE}$ genes due to TRH treatment, but instead resulted in significant additional decreases in pulmonary AOE mRNA levels at both 21 and $22 \mathrm{~d}$ of gestation. The tested AOE mRNA half-lives (stabilities) revealed no significant differences between controls (8.0-10.5 h) and TRH-treated (8.2-9.5 h) and TRH-plus-DEX treatment $(7.8-10.7 \mathrm{~h})$ groups. These findings suggest that prenatal treatment with TRH and with TRH plus DEX acts to depress the normal late fetal lung AOE activity elevations by (direct) negative regulation of AOE gene expression, and the decreased $A O E$ expression is likely regulated at the level of gene transcription rather than posttranscriptionally. (Pediatr Res 33: 171-176, 1993)
\end{abstract}

\section{Abbreviations}

AOE, antioxidant enzyme

CuZnSOD, copper-zinc superoxide dismutase

SOD, superoxide dismutase

MnSOD, manganese superoxide dismutase

CAT, catalase

GP, glutathione peroxidase

TRH, thyrotropin-releasing hormone

$T_{3}$, triiodothyronine

DEX, dexamethasone

cRNA, complementary RNA

The pulmonary AOE system is the primary intracellular antioxidant defensive system of the lung against oxygen toxicity ( 1 ,

Received February 27. 1992: accepted October 7. 1992.

Correspondence and reprint requests: Youwei Chen. M.D.. Pulmonary Research (R-120). University of Miami School of Medicine. P.O. Box 016960. Miami, FL 33101

Supported by the University of Miami School of Medicine, Pulmonary Research Center. Departments of Medicine and Pediatrics.
2). It has been demonstrated in each of the five different species examined to date-the rat, rabbit, guinea pig, hamster, and sheep-that development of the surfactant system and the lung AOE system share a chronologically similar late gestational pattern of development, and that the developing lung markedly increases both its surfactant content and its AOE activity levels during the final 10 to $15 \%$ of gestation (3-6). The late gestational rise in AOE (SOD, CAT, and GP) activities is considered to be a normal "preparation for birth" phenomenon that is required to assure safe respiratory functioning of the newborn's lung when it is suddenly exposed to several-fold-higher $\mathrm{O}_{2}$ tension immediately after birth than the $\mathrm{O}_{2}$ tension experienced in utero (3-5, 7).

We have previously demonstrated that, although prenatal administration of either $\mathrm{T}_{3}$ or $\mathrm{T}_{3}$ plus DEX to pregnant rats accelerated surfactant system development in the late fetal lung, both of these hormonal treatments significantly delayed or decreased pulmonary AOE system development (8). Further studies were done recently using the same hormonal agents (TRH instead of $\mathrm{T}_{3}$ ) that are currently being tested clinically to try to reduce the incidence/severity of respiratory distress syndrome in premature labor situations. Prenatal TRH administration to late pregnancy rats significantly increased fetal lung surfactant content but again significantly decreased normal pulmonary AOE levels late in gestation (9). Furthermore, the addition of DEX cotreatment did not reverse the inhibitory effect of TRH on lung AOE system development, but instead produced even greater activity depressions of some of the AOE than TRH treatment alone (9).

To further explore the mechanism by which prenatal treatment with TRH or TRH plus DEX depresses normal fetal lung AOE development, we undertook a series of experimental studies to examine the hypothesis that both hormonal treatments might act by (direct) negative regulation of $\mathrm{AOE}$ gene expression. The studies were designed to determine I) whether lowered AOE expression in the late fetal lung due to TRH or TRH-plus-DEX treatment will be associated with lowered specific AOE mRNA concentrations (i.e. a pretranslational mechanism); and 2) whether the depressed AOE gene expression is regulated at the level of gene transcription or at the posttranscriptional level.

\section{MATERIALS AND METHODS}

Animals and Treatment. Adult Sprague-Dawley albino female rats were bred by putting one male and two female rats in the same cage overnight, checking for sperm-positive vaginal smears the next morning, and considering the midpoint of the cohabitation period as the onset of pregnancy. The timed-pregnancy rats were maintained on standard laboratory food and water ad libitum and were kept on a 12-h light/dark cycle in the accredited University of Miami Animal Care Facilities. All of the animal 
treatment procedures in our experimental protocol were preapproved by the University's Committee on Research Animal Welfare.

At $48 \mathrm{~h}$ before premature delivery at gestation d 20 or 21 or term delivery on $\mathrm{d} 22$, pregnant rats were divided at random into hormonal treatment or control groups. For studies involving TRH treatment alone, prenatal TRH (Bachem Inc., Torrance, CA) was administered as a loading dose of TRH $(25 \mu \mathrm{g} / \mathrm{kg}$, s.c. $)$ at $48 \mathrm{~h}$ before delivery and by s.c. implantation of an Alzet osmotic minipump (Alza Corp., Palo Alto, CA) through which continuous TRH was administered $(100 \mu \mathrm{g} / \mathrm{kg} / \mathrm{d})$. The control groups received an equal volume s.c. injection of saline, as well as a "sham" operation under the similar ketamine:xylazine (Ketalar, $90 \mathrm{mg} / \mathrm{kg}$, Parke-Davis, Morris Plains, NJ; Rompun, 10 $\mathrm{mg} / \mathrm{kg}$, Cutler Labs, Shawnee, KS) anesthesia. For the studies examining prenatal TRH-plus-DEX combination therapy, TRH was administered as described above, and, in addition, dams received prenatal DEX (Schein Pharmaceutical, Inc., Port Washington, NY) at a dose of $0.4 \mathrm{mg} / \mathrm{kg}$ intraperitoneally at 48 and $24 \mathrm{~h}$ before delivery. This control group was treated the same as the above TRH controls, and, in addition, received an equal volume $(0.5 \mathrm{~mL} / 100 \mathrm{~g})$ of intraperitoneal saline instead of DEX. All of the above hormonal treatment procedures and dosages of TRH and TRH plus DEX were identical to those used previously in the earlier AOE activity studies in our laboratory (9), and it has been shown that prenatal TRH treatment resulted in significant increases in $\mathrm{T}_{3}$ and thyroxine serum levels in TRH-treated dams (9).

Forty-eight $\mathrm{h}$ after initiation of prenatal hormone treatment. rat fetuses of gestational age 20,21 , or $22 \mathrm{~d}$ were delivered by hysterotomy under pentobarbital sodium anesthesia. Fetuses were killed by an intraperitoneal injection of pentobarbital sodium followed by cutting the great vessels in the abdomen. Their lungs were perfused to whiteness immediately in situ with icecold saline via the pulmonary artery. The left atrial appendage was snipped off to facilitate drainage of the perfusate. The perfused lungs were then excised, stripped of nonpulmonary tissue, and either stored at $-70^{\circ} \mathrm{C}$ for later analysis or immediately processed for analysis. No differentiation between male and female fetuses was made.

Biochemical Analyses. cRNA preparation. The rat liver CAT cDNA clone, pMJ1010, was obtained from Dr. S. Furuta, Department of Biochemistry, Shinshu University School of Medicine, Nagase, Japan (10). The 1.1-kb Pst I-fragment was subcloned into pGEM-3Z (Promega Corporation, Madison, WI). After this recombinant plasmid was linearized, a ${ }^{35} \mathrm{~S}$-labeled antisense cRNA probe was synthesized using SP6 RNA polymerase and $\left[{ }^{35}\right.$ S]UTP (New England Nuclear Research Products, Boston, MA). An unlabeled sense cRNA was prepared with T7 RNA polymerase. It has been demonstrated that rat lung and liver express only one CAT mRNA species (11), so that the rat liver cDNA probe that we used is suitable to measure rat lung CAT mRNA concentration.

The plasmid DNA pKS-cGP-1 carrying rat liver GP cDNA $(\sim 0.9 \mathrm{~kb})$, was a gift from Dr. Y-S. Ho, Laboratory of Molecular Biology, Duke University Medical Center, Durham, NC (12). Because the vector (pBluescript II KS) contains T7 andT3 promoters allowing efficient in vitro synthesis of strand-specific RNA, the plasmid was therefore transformed back into Echerichia coli JM109 directly. After this plasmid was linearized, a ${ }^{35} \mathrm{~S}$ labeled antisense cRNA probe was prepared using T7 RNA polymerase and $\left[{ }^{35}\right.$ S $] U T P$. An unlabeled sense cRNA was synthesized with T3 RNA polymerase. Because rat lung has only one GP mRNA species (13), the rat liver CDNA probe we used is suitable to measure rat lung GP mRNA concentration.

Rat lung CuZnSOD cRNA was prepared as previously described (14), and the cRNA for MnSOD (15) and $\beta$-actin (cDNA provided by Dr. John Bixby, Department of Molecular and Cellular Pharmacology, University of Miami School of Medicine) were prepared in similar fashion. A pGEM-Blue construct containing the $3^{\prime}$-end of an $\alpha$-actin cDNA was used to synthesize actin $\left[{ }^{3} \mathrm{H}\right] \mathrm{cRNA}$ for use as an mRNA recovery marker (14). $m R N A$ quantitation. Total nucleic acids were isolated from lung tissue as previously described (14). About $5000 \mathrm{dpm}\left[{ }^{3} \mathrm{H}\right] \alpha-$ actin cRNA was added at the beginning of the extraction of total nucleic acids, and the radioactivity in a portion of isolated total nucleic acids was measured to determine mRNA recovery. Samples of total nucleic acid solutions were then exposed to the radiolabeled cRNA probe for CuZnSOD mRNA, MnSOD mRNA, CAT mRNA, GP mRNA, or $\beta$-actin mRNA to quantitate these $m R N A$ by solution hybridization (16). The unlabeled cRNA of CuZnSOD, MnSOD, CAT, GP, or $\beta$-actin were used as a standard with which we defined the range in which hybridization of each radiolabeled probe increased proportionally with added mRNA.

$m R N A$ degradation. The degradation rates of $\mathrm{CuZnSOD}$ mRNA, CAT mRNA, and GP mRNA were measured in vitro using gestational d 21 rat lung slices. Excised lungs were sliced with a Mcllwain tissue chopper (Brinkmann Instruments, Westbury, NY) set to make $1.0-\mathrm{mm}$ slices. Perfused lungs from an entire litter were pooled to obtain sufficient tissue for these experiments. The slices were incubated at $37^{\circ} \mathrm{C}$ at a shaking frequency of $120 \mathrm{cycle} / \mathrm{min}$ in $10 \mathrm{~mL}$ of Krebs-Ringer bicarbonate medium containing $5.5 \mathrm{mM}$ glucose, adult rat serum concentrations of $20 \mathrm{~L}$-amino acids and $10 \mu \mathrm{g} / \mathrm{mL}$ actinomycin $\mathrm{D}$ to block RNA synthesis (11). In all experiments, the medium was equilibrated with $95 \% \mathrm{O}_{2} / 5 \% \mathrm{CO}_{2}$ before use, and the incubations were carried out in a gas phase of $95 \% \mathrm{O}_{2} / 5 \% \mathrm{CO}_{2}$ (17). equilibrated with $95 \% \quad \mathrm{O}_{2} / 5 \% \quad \mathrm{CO}_{2}$ before use, and the incubations were carried out in a gas phase of $95 \% \mathrm{O}_{2} / 5 \% \mathrm{CO}_{2}$ (17). At $0,3,6$, and $9 \mathrm{~h}$ of incubation, a portion of the lung tissue was removed from the flask, washed in cold saline, and quickly frozen in liquid nitrogen. The tissue samples were stored at $-70^{\circ} \mathrm{C}$ until total nucleic acids were isolated and assayed for the amounts of CuZnSOD mRNA, CAT mRNA, and GP mRNA. The half-life of each mRNA was then calculated from the slope of its decay curve.

$D N A$. DNA in an aliquot of the lung homogenates was extracted and measured using calf thymus DNA (Sigma Chemical Co., St. Louis, MO) as a standard (18). Results of the AOE mRNA concentrations were expressed as the specific AOE mRNA molecules per mg DNA.

Statistical analysis. For each determination, the values for individual samples were averaged per experimental group, and the SD was calculated. Multiple-group comparisons were made by analysis of variance and Duncan's multiple-range test. Kramer's extension of Duncan's test was used in cases of unequal number of replications (19). A difference between groups was considered significant if $p<0.05$.

\section{RESULTS}

AOE $m R N A$ Concentration. Figure 1 from our previous data on AOE activity changes with prenatal TRH and TRH-plusDEX treatment is provided for comparison to the present AOE mRNA data. The late gestational development of the pulmonary AOE mRNA concentrations in control fetal lungs and lungs with prenatal TRH treatment is illustrated in Figure 2. At d 20 of gestation, CAT and GP mRNA levels in the TRH treatment groups were decreased compared with the control values, and at d 21 and d 22 of gestation there were statistically significant decreases in CuZnSOD mRNA ( $\downarrow 30 \%$ on $d 21 / \downarrow 37 \%$ on $d 22$ ), MnSOD mRNA $(\downarrow 26 \% / \downarrow 32 \%)$, CAT mRNA $(\downarrow 19 \% / \downarrow 26 \%)$, and GP mRNA $(\downarrow 34 \% / \downarrow 34 \%)$ concentrations compared with the control values.

The effect of combination prenatal treatment with TRH plus DEX on lung AOE mRNA concentrations is shown in Figure 3. The addition of DEX administration obviously did not reverse the lowered expression of lung AOE genes due to prenatal TRH treatment. Significantly depressed levels were found at gestational d 21 and 22 for most AOE mRNA quantitations, and for CuZnSOD mRNA ( $\downarrow 50 \%$ on $d 21 / \downarrow 46 \%$ on d 22$)$, CAT mRNA $(\downarrow 51 \% / \downarrow 46 \%)$, GP mRNA $(\downarrow 58 \% / \downarrow 48 \%)$, and MnSOD mRNA 


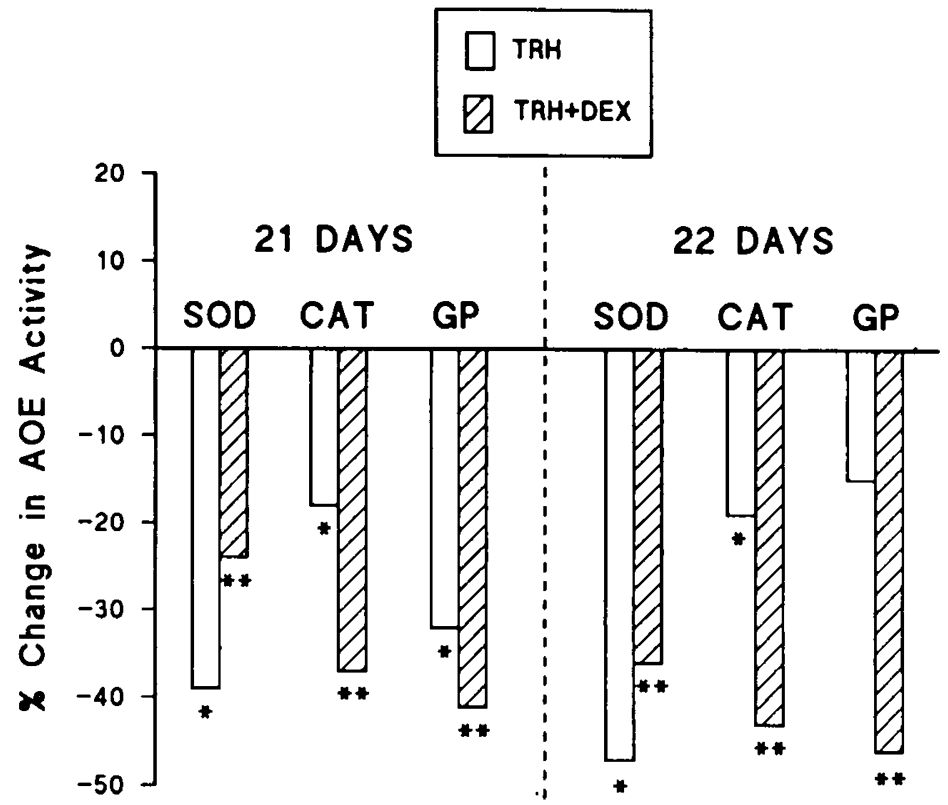

Fig. 1. Changes in late fetal rat lung AOE activities due to TRH and TRH-plus-DEX prenatal administration. The hormone treatment procedures and dosages are similar to those described in legends for Figures 2 and 3. Enzyme activities were calculated as activity units/mg DNA and are expressed here as the percentage of change from control (saline-treated) fetal lung values $\left(=0\right.$, baseline). ${ }^{*}, p<0.01$ for TRH activity levels versus control lung values. ${ }^{* *}, p<0.01$ for TRH-plus-DEX activity levels versus respective control lung values. Data from Rodriguez $\bullet l$ al. (9) with permission.

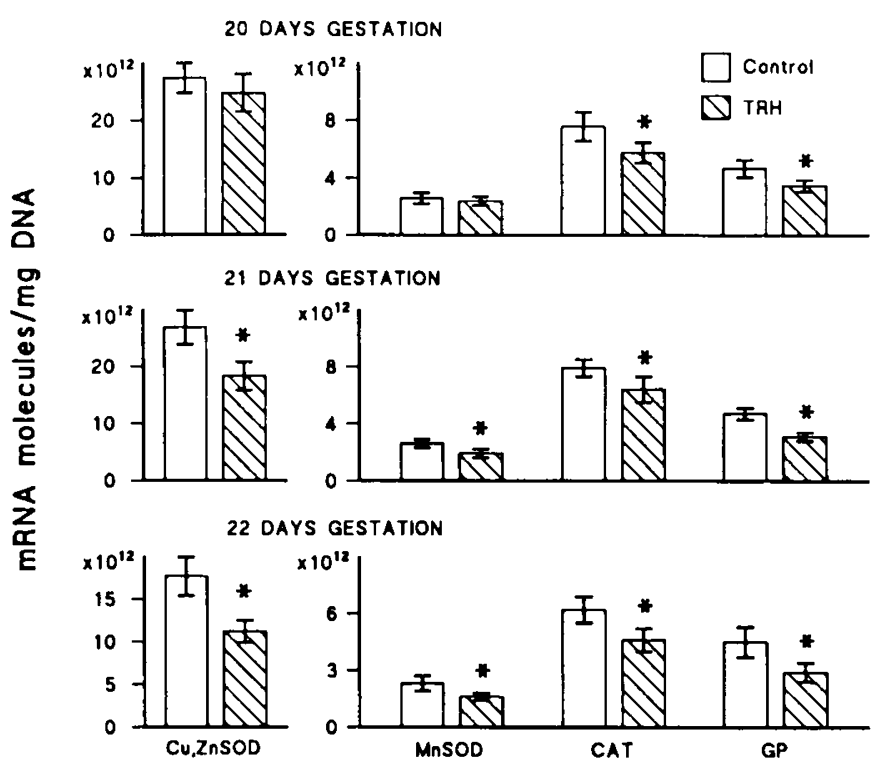

Fig. 2. Effect of prenatal TRH treatment on developing fetal rat lung AOE mRNA concentrations. Pregnant rats were administered TRH by loading dose $(25 \mu \mathrm{g} / \mathrm{kg}$ ) plus implanted minipumps (delivering TRH 100 $\mu \mathrm{g} / \mathrm{kg} / \mathrm{d}$ ) or equal volume saline (control) at $48 \mathrm{~h}$ before delivery of rat fetuses at gestational age 20,21, and $22 \mathrm{~d}$. Values are based on five to eight fetal lung samples (two litters) per group per gestational age; bars indicate mean $\pm 1 \mathrm{SD}$. ${ }^{*}$, Statistically significant with a $p<0.01$ for the TRH-treated compared with control group values.

( $\downarrow 38 \%$ on d 21 ) levels were even further depressed with DEX cotreatment than in the TRH-alone-treated fetal lungs.

The lung $\beta$-actin mRNA concentrations for $\mathrm{d} 21$ of gestation in the TRH-treated and TRH-plus-DEX-treated groups showed no significant differences for the hormonal-treated versus control groups. The values were (in units of $\beta$-actin mRNA molecules/ $\left.\mathrm{mg} \mathrm{DNA} \times 10^{-14}\right): 1.69 \pm 0.27(\mathrm{TRH}$-treated $)$ and $1.93 \pm 0.17$ (controls): $1.59 \pm 0.18$ (TRH + DEX-treated) and $1.79 \pm 0.11$

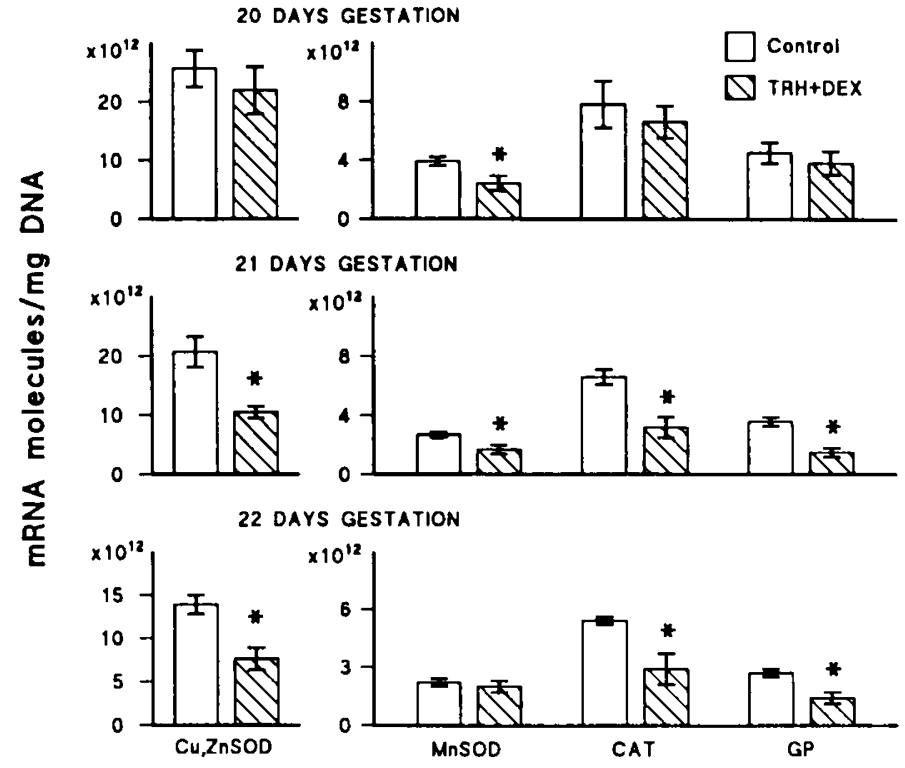

Fig. 3. Effect of prenatal TRH-plus-DEX treatment on developing fetal rat lung AOE mRNA concentrations. Prenatal administration of TRH or saline was similar to that described in the legend to Figure 2. In addition, pregnant rats received an intraperitoneal injection of either DEX $(0.4 \mathrm{mg} / \mathrm{kg} / \mathrm{d})$ or equal volume saline (control) at 48 and $24 \mathrm{~h}$ before premature delivery at 20,21 , and $22 \mathrm{~d}$ of gestation. Values are based on six to eight fetal lung samples (two litters) per group per gestational age; hars indicate mean $\pm 1 \mathrm{SD}^{*}, p<0.01$ for the TRHplus-DEX-treated compared with control group values.

(controls) (mean $\pm 1 \mathrm{SD}, n=5-6$, fetal lung samples/group, $p$ $>0.05$ hormone-treated versus respective controls).

AOE $m R N A$ Stability. Figure 4 illustrates the typical decay curves for AOE mRNA (CuZnSOD) from which the half-lives were calculated. The calculated AOE mRNA half-lives for d 21 of gestation for control, TRH-treated, and TRH-plus-DEXtreated groups are summarized in Table 1 . None of the AOE mRNA half-lives was significantly different in the hormonal 




Fig. 4. CuZnSOD mRNA degradation rate in control (saline), TRHtreated and TRH + DEX-treated $21-\mathrm{d}$ gestation fetal rat lung slices. Data from average of four experiments for TRH per treatment group and five experiments for TRH + DEX per treatment group. Slopes for lung slices: $-0.085 \pm 0.016$ (TRH-treated) and $-0.072 \pm 0.014$ (controls): $-0.071 \pm 0.016$ (TRH + DEX-treated) and $-0.069 \pm 0.015$ (controls). The calculated half-lives of CuZnSOD mRNA are listed in Table 1.

Table 1. Lung AOE $m R N A$ stability in TRH-treated, TRH + $D E X$-treated, and control offspring*

\begin{tabular}{lrrr}
\hline & \multicolumn{3}{c}{ mRNA half-life $(\mathrm{h})$} \\
\cline { 2 - 4 } & CuZnSOD & CAT & GP \\
\hline TRH treatment alone & & & \\
TRH $(n=4)$ & $8.2 \pm 2.5$ & $8.9 \pm 2.0$ & $9.5 \pm 2.0$ \\
Control $(n=4)$ & $9.6 \pm 2.2$ & $8.0 \pm 2.6$ & $9.2 \pm 1.8$ \\
TRH + DEX treatment & & & \\
TRH + DEX $(n=5)$ & $10.1 \pm 1.8$ & $7.8 \pm 2.2$ & $10.7 \pm 2.1$ \\
Control $(n=5)$ & $10.5 \pm 2.4$ & $8.4 \pm 2.4$ & $9.3 \pm 2.4$ \\
\hline
\end{tabular}

* Values are means \pm 1 SD for $n$ samples/group using lung slices from gestation d 21 rat litters. TRH and TRH + DEX treatment are as described in the figure legends and in Materials and Methods. None of the AOE mRNA half-lives was significantly different for the TRH treatment alone or for the TRH + DEX treatment group $v$ s the respective controls $(p>0.05)$.

treatment groups versus their respective control group values ( $p$ $>0.05)$.

\section{DISCUSSION}

Prenatal glucocorticoid treatment has been used for many years to try to reduce the incidence and severity of respiratory distress syndrome in threatened premature delivery (20). More recently, based on a variety of experimental (animal) evidence that thyroid hormone treatment combined with glucocorticoid treatment has an additive or synergistic effect on stimulating surfactant system development $(21,22)$, combined hormonal therapy has been tested clinically. However, because the human placenta is rather impermeable to thyroid hormone, thyroidreleasing hormone or TRH (which does cross the placenta) is the agent that combined with long-acting synthetic glucocorticoid hormone (betamethasone) is being used in incipient premature delivery situations $(23,24)$. Experimentally, TRH also appears to act in an additive or synergistic fashion with glucocorticoid in stimulating earlier lung surfactant system maturation $(25,26)$.

Previous studies from our laboratory have focused on hormonal effects on the normal late gestational development of another important lung biochemical system, i.e. the AOE system. The AOE-SOD, CAT, and GP-are the key protective system in aerobic cells that protect against the reactive $\mathrm{O}_{2}$ species that are formed as a byproduct of normal aerobic metabolism in cells. The pulmonary AOE defenses become especially critical under hyperoxic conditions when the rate of $\mathrm{O}_{2}$ radical production is known to markedly increase, as does the potential for pulmonary $\mathrm{O}_{2}$ toxicity $(1,2,27)$.

It has been previously demonstrated that during the final 10 to $15 \%$ of gestation in all animal species tested, there normally occurs a several-fold elevation in fetal lung AOE activities (3-6, $28,29)$. This normal pattern of late gestational rise on the AOE has been proposed to be nature's way of "preparing" the lung for its transition at the time of birth from the relatively hypoxic in utero environment $\left[\mathrm{Po}_{2} \cong 20-25 \mathrm{~mm} \mathrm{Hg}(2.7-3.3 \mathrm{kPa})\right]$ to the 5 -fold-higher $\mathrm{O}_{2}$ tensions that will eventuate with breathing $21 \% \mathrm{O}_{2}$ in the ex utero environment immediately after birth (3$5,7)$. Of interest is the associated finding that the chronology of the late gestational development of the AOE system was shown in all the species studied to closely parallel the late gestational maturation of the surfactant system (3-6). This finding suggested to us that perhaps both lung biochemical systems share common controlling factors in the fetal lung. And in fact, it was subsequently demonstrated that prenatal DEX treatment to pregnant rats resulted in the accelerated development of both the surfactant system (expected) and the lung AOE system (hypothesized) in the treated fetuses (30).

Prenatal treatment with either $\mathrm{T}_{3}$ or TRH, however, consistently resulted in stimulation of surfactant system development in the treated versus control fetal rats, but depressed the normal development of the AOE system $(8,9,31)$. Additionally, although combined $T_{3}$ or TRH-plus-DEX treatment had an increased or synergistic stimulatory effect on surfactant system maturation. DEX cotreatment not only did not reverse the depression of AOE system development produced by $\mathrm{T}_{3}$ or TRH treatment alone, but actually tended to exacerbate the $\mathrm{T}_{3}$ or TRH inhibitory effects on AOE activities $(8,9)$ (see Fig. 1).

The current molecular biology studies were thus undertaken to provide insight into the mechanism(s) by which TRH and TRH plus DEX might be controlling the normal gene expression of the protective AOE system in the late gestation fetal lung. Pleiotropic hormones such as these are reported to have either primarily transcriptional or primarily translational or posttranslational effects on different biochemical systems and different specific proteins, or may act to stabilize or destabilize mRNA (32-35). For example, it has been recently reported that glucocorticoid regulation of surfactant protein $B$ involves an effect on its mRNA stability (3-fold increase in mRNA half-life), whereas glucocorticoid treatment increases surfactant protein $C$ mRNA without any effect on the mRNA half-life (34). For intestinal lactase development, both glucocorticoid and $T_{3}$ treatment reportedly result in reduced lactase activity despite elevated lactase synthesis, indicating to the investigators a posttranslational effect of these two hormones in the developing gastrointestinal tract (35). More in line with our own studies, Clerch et al. (11) have recently reported that prenatal DEX treatment increases CAT mRNA levels in late fetal rat lung without a change in CAT mRNA stability, suggesting a gene transcriptional mechanism of action. Because of reports such as these and many others, we tried to approach these studies with no a priori assumptions as to the mechanisms of the prenatal hormonal effects on the AOE.

Our findings (Figs. 2 and 3) clearly indicate that TRH alone or TRH-plus-DEX treatment produced depressed levels of mRNA for each of the four AOE studied, in keeping with the depressed enzyme activities previously found to result from prenatal treatment with these agents (Fig. 1) (9). The lack of significant changes in $\beta$-actin gene expression ( $\mathrm{mRNA}$ ) with these hormonal treatments suggests that the pretranslational response of the AOE is at least partly specific. Whereas the quantitative mRNA data would suggest a transcriptional mode of action on AOE gene expression, the possibility of altered mRNA stability needed to be ruled out before such a conclusion could be more 
convincingly proposed. Although destabilization of the mRNA by hormonal treatments could be ruled out more definitively by pulse-chase type experiments, the lack of any difference in mRNA half-lives versus controls for any of the three AOE (Table 1) in the actinomycin D studies would seem to indicate that a mechanism of altered stability of mRNA transcripts by these hormones is unlikely. Thus, we conclude that the mechanism of depression of the normal developmental elevation of AOE activity levels in the late fetal lung is very likely due to (direct) hormonal action of TRH and TRH plus DEX on transcription of the AOE genes. Although additional effects of TRH and TRH plus DEX on translational and posttranslational processes are still possible, the reasonably close similarity of AOE activity changes and AOE mRNA changes found in the present and the earlier studies (Fig. 1 compared with Figs. 2 and 3 ) suggests that these other possible hormonal effects on gene expression are also unlikely.

The finding that TRH or $\mathrm{T}_{3}$ treatment has depressing effects on lung biochemical development (AOE system) is actually not as unique as it first appears to be. Whereas $\mathrm{T}_{3}$ or TRH has previously been considered a positive regulator of surfactant system development, newer studies have made it necessary to reevaluate hormonal effects on lung biochemical system maturation. For example, Pope and Rooney (36) found that, whereas DEX treatment stimulated fetal lung fatty acid synthase enzyme development (enzyme involved in de novo fatty acid synthesis for surfactant production), prenatal $T_{3}$ treatment acted to inhibit fatty acid synthase development. Newer studies of the hormonal effects on the late gestational appearance of the surfactantassociated proteins (SP-A, SP-B, SP-C) have indeed made the story even more complex (37). For example, whereas prenatal glucocorticoid treatment reportedly results in increased mRNA levels for SP-A and SP-B (38), $T_{3}$ treatment, in contrast, tends to depress the accumulation of SP-A and SP-B mRNA in the late fetal lung $(39,40)$. Although some of the above studies may involve high (nonphysiologic) doses of $T_{3}$, nevertheless, the earlier notion that $\mathrm{T}_{3}$ and DEX have additive or synergistic hormonal influences on nearly all aspects of late gestational lung development is likely no longer a valid concept.

Although it has been demonstrated that development of the lung AOE system has a similar normal pattern of late gestational rise in the five animal species tested, newer studies indicate that perhaps AOE development in different species does not necessarily have similar hormonal control mechanisms. For example, Walther et al. (41) found that, whereas corticosteroids increased AOE activities in preterm lamb lungs, prenatal TRH alone or TRH added to corticosteroids had no negative (or positive) effects on the pulmonary AOE activities. Also, although prenatal DEX treatment accelerated late fetal rat lung AOE system development and produced more elevated AOE responses to hyperoxic challenge in newborn rats $(30,42)$, the same prenatal DEX treatment regimen in rabbits resulted in a lack of increase in fetal lung AOE levels and failed to reverse the inability of premature rabbits to induce AOE during hyperoxic exposure (43). Unfortunately, there are, to date, no data regarding hormonal regulation of the AOE system in human lung. Clinical trials with combined TRH and glucocorticoid treatment have shown a lesser incidence of bronchopulmonary dysplasia in very-low-birth-weight infants but surprisingly no significant decrease in the incidence or severity of respiratory distress syndrome (24). The reported decrease in bronchopulmonary dysplasia (18 versus $44 \%$ in untreated infants) in these premature infants treated with high fractional inspired $\mathrm{O}_{2}$ levels would seem to represent an apparent disparity with our experimental findings of decreased $\mathrm{AOE}$ defenses due to similar combined hormonal treatment.

However, recently published evidence from our laboratories demonstrates that despite depressed baseline pulmonary AOE levels at birth, the newborn animals prenatally treated with TRH or TRH plus DEX are actually able to induce a normal or even an enhanced $\mathrm{AOE}$ response to high $\mathrm{O}_{2}$ exposure (9). These experimental findings would tend to be more in line with the clinical findings reported to date with prenatal TRH and glucocorticoid use.

Acknowledgments. The authors thank Dr. Shuichi Furuta for providing the catalase cDNA clone, Dr. Ye-Shih Ho for providing the glutathione peroxidase cDNA clone, and Dr. John Bixby for providing the $\beta$-actin cDNA clone. We are also grateful to Drs. Maria Rodriguez-Pierce, Ilene Sosenko, and Luciano Blanco for their helpful discussion; and Martha Sanchez for her patient assistance with the manuscript preparation.

\section{REFERENCES}

1. White CW 1988 Pulmonary oxygen toxicity: Cellular mechanisms of oxidant injury and antioxidant defense. In: Bancalari E, Stocker JT (eds) Bronchopulmonary Dysplasia. Hemisphere, Cambridge, MA, pp 22-41

2. Huber GL, Drath DB 1981 Pulmonary oxygen toxicity. In: Gilbert DL (ed) Oxygen and Living Processes: An Interdisciplinary Approach. SpringerVerlag, New York, pp 273-342

3. Frank L, Sosenko IRS 1987 Prenatal development of lung antioxidant enzymes in four species. J Pediatr 110:106-110

4. Frank L, Sosenko IRS 1987 Development of lung antioxidant enzyme system in late gestation: possible implications for the prematurely born infant. $J$ Pediatr 110:9-14

5. Sosenko IRS. Frank L 1987 Guinea pig lung development: antioxidant en zymes and premature survival in high $\mathrm{O}_{2}$. Am J Physiol 252:R693-R698

6. Walther FJ, Wade AB, Warburton D, Forman HJ 1991 Ontogeny of antioxidant enzymes in the fetal lamb lung. Exp Lung Res 17:39-45

7. Frank L, Groseclose EE 1984 Preparation for birth into an $\mathrm{O}_{2}$-rich environment: the antioxidant enzymes in the developing rabbit lung. Pediatr Res $18: 240-244$

8. Sosenko IRS, Frank L 1987 Thyroid hormone depresses antioxidant enzyme maturation in fetal rat lung. Am J Physiol 253:R592-R598

9. Rodriguez MP, Sosenko IRS, Antigua MC, Frank L 1991 Prenatal hormone treatment with thyrotropin releasing hormone and with thyrotropin releasing hormone plus dexamethasone delays antioxidant enzyme maturation but does not inhibit a protective antioxidant enzyme response to hyperoxia in newborn rat lung. Pediatr Res 30:522-527

10. Furuta S, Hayashi H, Hijikata M, Miyazawa S, Osumi T, Hashimoto T 1986 Complete nucleotide sequence of cDNA and deduced amino acid sequence of rat liver catalase. Proc Natl Acad Sci USA 83:313-317

11. Clerch LB, Iqbal J, Massaro D 1991 Perinatal rat lung catalase gene expression influence of corticosteroid and hyperoxia. Am J Physiol 260:L428-L433

12. Ho Y-S, Howard AJ, Crapo JD 1988 Nucleotide sequence of a rat glutathione peroxidase cDNA. Nucleic Acids Res 16:5207

13. Rahman I, Clerch LB, Massaro D 1991 Rat lung antioxidant enzyme induction by ozone. Am J Physiol 260:L412-L418

14. Hass MA. Iqbal J, Clerch LB, Frank L. Massaro D 1989 Rat lung Cu, Zn superoxide dismutase. Isolation and sequence of a full-length cDNA and studies of enzyme induction. J Clin Invest 83:1241-1246

15. Ho Y-S, Crapo JD 1987 Nucleotide sequences of cDNAs coding for rat manganese-containing superoxide dismutase. Nucleic Acids Res 15:10070

16. Durnam DM, Palmiter RD 1983 A practical approach for quantitating specific mRNAs by solution hybridization. Anal Biochem 131:385-393

17. Clerch LB, Whitney PL, Massaro D 1987 Rat lung lectin synthesis, degradation and activation. Biochem J 245:683-690

18. Schneider WC 1957 Determination of nucleic acids in tissue by pentose analysis. Methods Enzymol 3:680-684

19. Steel RGD, Torrie JH 1960 Principles and Procedures of Statistics. McGrawHill, New York, pp 107-109, 114

20. Collaborative Group on Antenatal Steroid Therapy 1981 Effect of antenatal dexamethasone administration on the prevention of respiratory distress syndrome. Am J Obstet Gynecol 141:276-287

21. Smith BT, Sabry K 1983 Glucocorticoid-thyroid synergism in lung maturation: a mechanism involving epithelial-mesenchymal interaction. Proc Natl Acad Sci USA 80:1951-1954

22. Gross I, Dynia DW, Wilson CM, Ingleson LD, Gewolb IH, Rooney SA 1984 Glucocorticoid-thyroid hormone interactions in fetal rat lung. Pediatr Res 18:191-196

23. Morales WJ, O’Brien WF. Angel JL, Knuppel RA, Sawai S 1989 Fetal lung maturation: the combined use of corticosteroids and thyrotropin-releasing hormone. Obstet Gynecol 73:111-116

24. Ballard RA, Ballard PL, Creasy RK, Padbury J, Polk DH, Bracken M. Moya FR, Gross I (and the TRH Study Group) 1992 Respiratory disease in verylow-birthweight infants after prenatal thyrotropin-releasing hormone and glucocorticoid. Lancet 339:510-515

25. Rooney SA, Marino PA, Gobran LI, Gross I, Warshaw JB 1979 Thyrotropinreleasing hormone increases the amount of surfactant in lung lavage from fetal rabbits. Pediatr Res 13:623-625

26. Ikegami M, Jobe AH, Pettenazzo A, Seidner SR, Berry DD, Ruffini L 1987 Effects of maternal treatment with corticosteroids. $\mathrm{T}_{3}, \mathrm{TRH}$ and their com binations on lung function of ventilated preterm rabbits with and without surfactant treatments. Am Rev Respir Dis 136:892-898 
27. Freeman BA. Topolsky MK. Crapo JD 1982 Hyperoxia increases oxygen radical production in rat lung homogenates. Arch Biochem Biophys 216:477-484

28. Tanswell AK. Freeman BA 1984 Pulmonary antioxidant enzyme maturation in the fetal and neonatal rat. I. Developmental profiles. Pediatr Res 18:584587

29. Gerdin E. Tyden O, Eriksson UJ 1985 The development of antioxidant enzymatic defense in the perinatal rat lung: activities of superoxide dismutase, glutathione peroxidase, and catalase. Pediatr Res 19:687-691

30. Frank L. Lewis PL. Sosenko IRS 1985 Dexamethasone stimulation of fetal rat lung antioxidant enzyme activity in parallel with surfactant stimulation. Pediatrics 75:569-574

31. Antigua MCB, Sosenko IRS, Frank L 1989 Thyrotropin releasing hormone (TRH) depresses antioxidant enzyme maturation in fetal rat lung. Pediatr Res 25:46A(abstr)

32. Kesavan P. Mukhopadhayay S, Murphy S, Rengaraju M, Lazar MA, Das M 1991 Thyroid hormone decreases the expression of epidermal growth factor receptor. J Biol Chem 266:10282-10286

33. Schellhase DE, Shannon JM 1991 Effects of maternal dexamethasone on expression of SP-A. SP-B and SP-C in the fetal rat lung. Am J Respir Cell Molec Biol 4:304-312

34. Venkatesh VC, Ertsey R, Ballard PL 1992 Differential glucocorticoid regulation of surfactant proteins B and C. Pediatr Res 31:55A(abstr).

35. Yeh K-Y, Yeh M. Holt PR 1991 Thyroxine and cortisone cooperate to modulate postnatal intestinal enzyme differentiation in the rat. Am J Physiol 260:G371-G378

36. Pope TS. Rooney SA 1987 Effects of glucocorticoid and thyroid hormones on regulatory enzymes of fatty acid synthesis and glycogen metabolism in developing fetal rat lung. Biochim Biophys Acta 918:141-148

37. Gross I 1990 Regulation of fetal lung maturation. Am J Physiol 259:L337 L344

38. Connelly IH, Hammond GL, Harding PGR. Possmayer F 1991 Levels of surfactant-associated protein messenger ribonucleic acids in rabbit lung during perinatal development and after hormonal treatment. Endocrinology 129:2583-2591

39. Nichols KV. Floros J, Dynia DW, Veletza SV, Wilson CM, Gross I 1990 Regulation of surfactant protein A mRNA by hormones and butyrate in cultured fetal rat lung. Am J Physiol 259:L488-L495

40. Floros J, Gross I. Nichols KV, Veletza SV, Dynia D, Lu H. Wilson CM Peterec SM 1991 Hormonal effects on the surfactant protein B (SP-B) mRNA in cultured fetal rat lung. Am J Respir Cell Mol Biol 4:449-454

41. Walther FJ, Ikegami M, Warburton D. Polk DH 1991 Corticosteroids, thyrotropin-releasing hormone, and antioxidant enzymes in preterm lamb lungs. Pediatr Res 30:518-521

42. Frank L 1992 Prenatal dexamethasone treatment improves survival of newborn rats during prolonged high $\mathrm{O}_{2}$ exposure. Pediatr Res 32:215-221

43. Sosenko IRS. Frank L 1992 Antenatal dexamethasone fails to reverse the inability of premature rabbits to induce antioxidant enzymes during hyperoxic exposure and decreases survival. Pediatr Res 31:323A(abstr) 